Diana Damian Martin. On Libraries, Performance Research Submission.

\author{
Library of Unfinished Texts \\ By Diana Damian Martin
}

The library of unfinished....is a project... something other etc

A text is being written (a critique, perhaps). A text is being written about something. A text is being enacted. A text performs itself. A text emerges in digital noise, poised between being and not being. A text discloses its place, coming to you, being thought. A text takes shape, and falls on the sides, and the paragraphs that make it up collide and vanish. This text enters a library; the library is formed of many such texts, scribbles with no home, forgotten paragraphs, drafts never sent: a kaleidoscope of dusty, unfinished criticism, of reference points whose dialogue was never finished.

Start with Hannah Arendt, to connect up the proposition of thinking as a process of withdrawing, and move to criticism as a performance of thinking. 1 wish I had time to 'show' Yvonne Rainer's Hand Movie from 1966, and talk about how that dance culture led to this openness towards critical processes.

The Library of Unfinished Texts is a project in process commissioned by Something Other, a research platform exploring relationships between writing, documentation and performance in the digital age. The Library... provides an open call out for discarded texts, texts that have not yet been published, the kinds that litter digital archives and fall down in priority on to do lists. As such, it is in itself a temporary repository.

Lam writing a text. I am writing this text for you. I remember, how this text same about, and it sits here, with other texts, different degrees of readiness, different degrees of completion.

It is, of course, also an inherent paradox. Since the $19^{\text {th }}$ century, emerging out a development of a public sphere that was in equal ways social as it was political (Habermas 1989, Fraser 2014), the library has existed as a space in 
Diana Damian Martin. On Libraries, Performance Research Submission.

which works are collected, and made available to a particular audience. This might suggest that the library is no place for unfinished thought - it is, as Jorge Luis Borges proposes in The Library of Babel, all thought.

In the UK, the library is also thought under threat, it is access to thought that has been closed down, discarded, disbanded, and because of that, ever more outside of its fiscal challenges, ever more indebted to a nomadic humanism.

But in Borges, we also find the infidels, and it is they who are of interest to me here. The infidels are those who claim that libraries are 'non-sense' (1994: 117) and whilst this negation holds a political resonance too bold for the margins of this brief essay, it offers the possibility of a library as being the space in which non-sense might reside. Non-sense, not as a negation, but a kind of thinking in process, a thought that has not yet arrived; non-sense as a process of disclosure, confused, without context.

CIRCULATION, or 'An unfinished paragraph on Sonia Delaunay's exhibition at Tate Modern'

[Outside Sonia Delaunay's retrospective at Tate Modern, in the cavernous belly of the turbine hall, a large glitter ball will be suspended from the ceiling. It wavers in mid-air, AV Technicians and Engineers, like a Laurel and Hardy sketch, maniacally gesturing "this way" or "to the left".

Perhaps a nod to Oleg Kulick's Armadillo as part of Live Culture in 2003 Musee de la Dance is set to begin for a weekend in May. Two floors above this to-ing and fro-ing of props and set, sits [filled with costumes]

Sonia Delaunay's retrospective draws and gives motion, through and in her own works. Works such as Syncopated Rhythm give rhythm to the costumes that once gave dynamism and movement The retrospective stills and de-stills itself. 
Diana Damian Martin. On Libraries, Performance Research Submission.

Heading toward abstraction and

the real-life subject depiction of works like Yellow Nude, Prose on the TransSiberian Railway compacts an expression of colour through poetry and vice versa. ]

I am interested in how The Library... forms a link between this thinking from, on, and about performance, in its many guises, and lacking the formal context that frames it, and criticism, as the site of ultimate, focused, completion of thought. In fact, it is The Library... that enables an encounter between fragments of critique at its different stages, and the library as a digital space of investigation. It is an exposure of subjectivity in its conflict with interpretation that situates criticism in a space of in-betweens that is as poetic as it is political.

The Library... stemmed from my own interests in exploring how criticism, as a reflective activity, can perform its processes, and therefore, engages in an opening up of taxonomies, methods, and histories that make up criticism in performance.

In Against Interpretation (1964), writer and critic Susan Sontag argues for a rethinking of the project of interpretation that allows the appearance, rather than usurping, of a work of art. Appearance, to Sontag, means 'experiencing the luminousness of the thing in itself' (1964: 10). To her, this approach to criticism acknowledges in equal measure the form and content of a work of art, and strives to give it visibility, rather than to excavate its meaning.

If we follow this line of thought, several aspects of criticism become apparent in Sontag's delineation. Firstly, criticism is an aesthetic practice as much as it is one of interpretation. This is evident in the ways in which Sontag articulates the possibility that criticism might render a work of art invisible. Secondly, there is a strong relationship between criticism and that to which it refers. Sontag's claim suggests a further nuance: that there is a power play between meaning and appearance in criticism. If we understand politics to refer to modes of governance as well as to modes of relating to and engaging with 
Diana Damian Martin. On Libraries, Performance Research Submission.

situations of power, this play becomes a matter of politics. Sontag's

proposition invites us to imagine criticism as an operation of politics and

aesthetics.

Sontag proposes that art is a process of appearance, and that criticism, in its relationship to it, can destroy that becoming visible as much as it can contribute to its coming into being. She calls for a criticism that 'should be to show how it is what it is, even that it is what it is, rather than to show what it means' (1964:14) This aesthetic attention to criticism is revealing of the relationship that criticism, albeit conceptually, has to process. The kind of criticism that Sontag calls for, is also one that doesn't just foreground the appearance of the work, it is also one that discloses its own making.

The Library... is dependant on the kinds of fragments, digital scraps and not yet formed ideas as legitimised by the library, that space in which that which has no immediate context gains infinite relationality. In other words, the project reveals, by its nature, the processes of thought at the heart of these unfinished critiques, in order to lay them bare, usurp the author as public persona, and allow space for thinking as an inherently personal, and private activity.

REFERENCE, or 'An unfinished paragraph on Ron Athey and Jerry Lee Lewis, and their shared religious upbringing'

[It can't be hard to see why the circus-tent revivalism and Pentecostalism provide such a ferocious performance school. Within the church the Bible is infallible and sacrosanct, the literal word of God and within it all the power of his voice. Within the church the preacher commands with the word, summoning an elemental noise that forces its way from the pit of a supplicant's shoes and through his gritted teeth to explode in an unintelligible burst. It is a Gift of the Spirit, a mark of devotion and belief. Athey's group performance, Gifts of the Spirit: Automatic Writing, places a vast machine of automatic writers; another gift and one Athey himself struggled with in his adolescence, alongside a table of vocalists. Seated around a séance table, 
Diana Damian Martin. On Libraries, Performance Research Submission.

blending spiritualism and Christianity in the best traditions of the Pentecostal church, placed under hypnosis and infused with the power of the occasion, they regularly erupt in a chorus of tongues, interspersing Athey's reading of his unfinished memoirs. [...]In the work of Athey and Jerry Lee Lewis words and guttural noises come tumbling out, stumbling over each other in the passion of delivery. From the storefront and tent churches of their childhood, speaking in tongues has left neither performer. Lewis, who replaces lyrics lost to his beer-dulled mind with yelps, howls and hammering piano, is overcome with a different fervor, music not God. Athey breaks his own text, memories of a painful childhood, with shouts and noise in the same way. Both are estranged from the church (although Lewis returns occasionally) but they draw on its form, passion and spirit as expressed through explosive and sudden babbling. ]

In the midst of the Cold War, as a reluctant immigrant in America, Arendt insists that thinking is an activity of both withdrawal and appearance.

Philosopher Hannah Arendt speaks about thinking in her (appropriately) unfinished The Life of the Mind (1971). To Arendt, thinking as an activity 'gives rise to doubt of the world's reality and my own' (1971: 49). It 'can seize upon and get hold of everything real [as] realness is the only property that remains stubbornly beyond its reach' (ibid.). To Arendt, thinking is a process through which the self withdraws, only to return to the realm of appearance where, crucially, meaning is derived through an encounter with processes of common sense-making. Appearance, Arendt proposes, is that which carries an indication of thought's realness.

Between Sontag and Arendt, I find a poetics of writing unfold. In the fragments of texts that also rest on this page, both those that once made up this essay and, those of unfinished texts without purpose, a kind of double process is revealed. On the one hand, the library here acts as a site that gives them legitimacy, that poises them between thought that has emerged, and interpretation that has not quite taken shape. And on the other, they exist on a threshold between sense and non-sense, orientation and de- 
Diana Damian Martin. On Libraries, Performance Research Submission.

contextualisation. They are no longer solely in the archives of their authors, nor entirely subdued by the noise of the internet; they have neither appeared, nor remained hidden. And importantly, they have not been excavated, for no formalisation of thought has yet taken place.

STACKS MAINTENANCE, or 'a series of unfinished paragraphs on an unfinished journal'.

['The North Wind Review was the title of the journal I had set out to launch in November 2004, while I was a graduate student at Columbia University in New York. I was furious at the state of politics worsening in the post-9/11 regime, and wanted a forum for grieving and imagining a new world. [...]

The North Wind is a cold wind; the radical critic and philosopher Roger Caillois (1913-1978) wrote "Le vent d'hiver" in 1937 for the Collège de Sociologie (spearheaded by Caillois, Georges Bataille and Michel Leiris), calling for a rigorous, arctic, and subversive wind that would sweep over the world and bring with it a new historical order. I don't know that we will succeed in achieving a new world order, nor what that would look like. But if we are in an extended economic depression, rent through with wars against slumdwellers, migrants, women, then surely it is also a propitious time to dream. The North Wind Review then is also a site for intellectual peregrinations, creative digressions, critiques, aphorisms, forays... anything that resists, troubles, intercepts, and disrupts the relentless regime of our "society of control" (Deleuze 1990 [1992]).

Pages can include:

\section{Reading list}

Links

Emergent Thought

stepnotbeyond

Table Talk

Hive] 
Diana Damian Martin. On Libraries, Performance Research Submission.

I am still nostalgic about the physical spaces that libraries occupy, and the conceptual propositions they make possible onto a space.

The internet is not the library some had hoped it might become; it is has not assimilated the material, cultural, civic and social dimension of libraries in their physical reality. The internet is not an expression of unlegislated terrain or accessible, encyclopaedic landscapes. It does, however, spill into material life. As such, its noisy, legislated, truncated nature provides a productive conflict with the library, as a conceptual accumulation of ideas and thoughts. The Library... remains an expression of thought yet to appear, of critique yet to be oriented, but it also displays the privacy of authorship without undermining its legitimacy, or appropriating its meaning in public.

I am writing a text. I am writing this text for you. I remember how this text came about, and it sits here, with other texts, different degrees of readiness and completion, and I no longer know what is finished, and what remains to be finished. Because a text is also being polished. I am polishing this text for you, and others and are helping me polish this text for you.

Word Count: 2320

\section{$\underline{\text { References: }}$}

Arendt, Hannah. (1971). The Life of the Mind: Thinking. London: Secker \& Warburg

Church, Lewis. (2011). Reference. Fragment from 'An unfinished paragraph on Ron Athey and Jerry Lee Lewis, and their shared religious upbringing' Gotman, Kelina. (2014). Stacks Maintenance. Fragment from 'A series of unfinished paragraphs on an unfinished journal'. Habermas, Jürgen.(1989). The Structural Transformation of the Public Sphere: An Inquiry into a Category of Bourgeois Society. Cambridge: Polity 
Diana Damian Martin. On Libraries, Performance Research Submission.

Fraser, Nancy. (1990). 'Rethinking the Public Sphere: A Contribution to the Critique of Actually Existing Democracy', Social Text, 25.25, 56-80

Sontag, Susan. (1964). Against Interpretation and Other Essays (London: Penguin)

White, Bryony. (2015). Circulation. Fragment from 'An unfinished paragraph

Deleted: 6 on Sonia Delaunay's exhibition at Tate Modern' 